\title{
Reducing the Impact of Environmental Noise on Quality of Life Requires an Effective National Noise Policy
}

\author{
Andrew S. Harris \\ Andrew S. Harris, Inc \\ 19 University Lane, Manchester, MA 01944 USA \\ asharrisinc@aol.com \\ Gregg G. Fleming \\ Volpe National Transportation Systems Center \\ 55 Broadway, Cambridge, MA 0213 USA \\ fleming@volpe.dot.gov \\ William W. Lang \\ International INCE \\ P.O. Box 3067 Arlington Branch, Poughkeepsie, NY 12603 USA \\ langww@juno.com \\ Paul D. Schomer \\ Schomer and Associates \\ 2117 Robert Drive, Champaign, IL 61821 USA \\ schomer@schomerandassociates.com \\ Eric W. Wood \\ Acentech Incorporated \\ 33 Moulton Street, Cambridge, MA 02138 USA \\ ewood@acentech.com
}

Suggested primary INCE subject classification number: 82

The focus here is on the impact of environmental noise on the quality of life. After reviewing the terms of The Noise Control Act of 1972 (NCA 72) related to quality of life, the authors explore the following issues: (1) the desire for an acceptable quality of life; (2) the absence of an effective national noise policy; (3) changes in the noise exposure of the U.S. population; (4) changes in the population (numbers, locations and desires); (5) changes in sources (numbers, locations and noise characteristics); and (6) inadequacy of knowledge about the effects of noise. The conclusion is drawn that a more effective national noise policy is required to achieve an acceptable quality of life for all Americans. 


\section{INTRODUCTION}

This paper considers the impact of environmental noise on the quality of life (QOL) in the United States and expresses the need for a more effective National Noise Policy (NNP). The Noise Control Act of 1972 (NCA 72) defined the first U.S. NNP ${ }^{1}$. NCA 72 produced a number of useful results. However, most factors considered during the development of NCA 72 and during the period of its immediate implementation have changed. All the major variables-population characteristics, noise sources, and the acceptability of various levels of sound--are different from their values in the past, but NCA 72 has not been brought into the $21^{\text {st }}$ century. Furthermore, the structures of NCA 72 have been dismantled or ignored for at least 20 years.

Individual assessments of quality of life are generally subjective. Recognizing that noise is unwanted sound, one could say, "noises are sounds that adversely impact an individual's quality of life." In this paper we use the term "noise" even as we recognize that one person's noise may be another person's "music". Complaints about environmental noise continue to increase in the United States. Various studies have identified specific noise effects that may diminish the quality of life. These effects include: interference with speech communication, sleep disturbance, physiological effects, interference with the learning process in schools, interference with leisure time and recreational activities, and reduction of residential property values. The percentage of the population highly annoyed at various levels of noise exposure continues to be the primary descriptor of adverse responses to noise, although there is considerable variation in response that relates to circumstances and the affected population.

Environmental noise levels are directly related to population density. Population density has changed and continues to change throughout the country, in urban, suburban, and rural areas ${ }^{2}$. The character of the population is changing as well. The middle-class, Caucasian values that dominated consideration of noise when NCA 72 was passed do not reflect the increasingly complex makeup of U.S. society. The urban population is increasing at twice the rate of the nonurban population in the United States, and the number of noise sources is increasing at a greater rate than the rate of increase of population. Although some major noise sources, such as commercial aircraft, have been substantially quieted through retrofit or replacement of major noise-producing technologies, the number of people adversely impacted by noise is increasing.

Despite the gains achieved as a result of NCA 72 and independently of it, vital needs are being ignored. NCA 72, although still on the books, is not effective enough and is not being adequately enforced. A more effective NNP is essential, and it is doubtful that NCA 72 can be rehabilitated through amendment. 


\section{WHY THE UNITED STATES NEEDS A MORE EFFECTIVE NNP}

\subsection{All People Desire an Acceptable Quality of Life}

We all desire an acceptable quality of life. However, this term means different things to different people. Many factors combine to make identification of an acceptable "quality of life" elusive:

- Individual definitions of "quality" differ. Let's consider "quiet" as an example. A city dweller's "quiet" may be a country-dweller's "unbearably noisy." Conversely, a country dweller's "quiet" may be a city dweller's unbearably "creepy." Such definitions vary widely among ethnic groups, families, and different parts of the country.

- Solving one problem may create another. For example, moving Denver's airport to a new location dramatically reduced the aircraft noise impact in the Denver area - at the cost of decreased convenience in access to the airport for all originating and terminating passengers.

- Our tolerance for each other and for the noise we make has been decreasing. This change in tolerance may have been decreasing faster than the reduction in noise at its source (emission) or in terms of Day-Night Noise Level (DNL) and other noise exposure (immission) metrics.

Annoyance is the most commonly used measure of the many adverse effects of environmental noise, and the absence of annoyance may be taken as an indicator of the quality of life. In 1972, the U.S. Congress recognized the need for a federal-level advocate to promote a peaceful quality of life. Such advocacy is still needed at the senior levels of government, perhaps now more than ever as both the population and the noise of the United States continue to grow.

Some people say that environmental noise is simply a local issue best dealt with at the local level. But noise consultants who work with state and local agencies and boards know that they do not have the technical knowledge to make informed decisions and develop adequate regulations governing noise, and they do not have the resources to enforce such regulations effectively. One component of a new NNP must be the development and dissemination of the resources, education, and data bases needed by state and local agencies and boards to effectively regulate and control local sources of excessive environmental noise.

\subsection{There Is No Effective National Noise Policy at This Time}

NCA 72 established the first NNP in the U.S. Because of built-in compromises, however, NCA 72 fell short of its authors' goals. NCA 72 is still on the books, but is not being enforced. The regulations and reports produced as a result of the NCA 72 are still the best we have in many situations, but they are woefully out of date. NCA 72 has not been updated since 1978, and there is very little coordination between the noise policies of various federal agencies. 


\subsection{People Are Still Exposed to Environmental Noise That May Adversely Affect "Health and Welfare"}

In NCA 72, Congress declared that, “...it is the policy of the United States to promote an environment for all Americans free from noise that jeopardizes their health or welfare." 3 The Environmental Protection Agency "Levels Document" 4 interprets "health and welfare" as follows:

The phrase "health and welfare" as used herein is defined as "complete physical, mental and social well-being and not merely the absence of disease and infirmity". This definition would take into account sub-clinical and subjective responses (e.g., annoyance or other adverse psychological reactions) of the individual and the public. As will be discussed below, the available data demonstrate that the most serious clinical health and welfare effect caused by noise is interference with the ability to hear. Thus, as used in this document, the phrase "health and welfare" will necessarily apply to those levels of noise that have been shown to interfere with the ability to hear.

The phrase "health and welfare" also includes personal comfort and well-being and the absence of mental anguish and annoyance. In fact, a considerable portion of the data available on the "health and welfare" effects of noise is expressed in terms of annoyance. However, "annoyance" is a description of the human reaction to what is described as noise "interference"; and though annoyance appears to be statistically quantifiable, it is a subjective reaction to interference with some desired human activity... Of the many community surveys on noise which have been conducted, speech interference emerges as the most tangible component of annoyance, whereas sleep and other kinds of activity interference are important, but less well-defined contributors. Thus, although it is important to understand the importance of annoyance as a concept, it is the actual interference with activity on which the levels identified in this document are based. ${ }^{4}$

The identified levels, always presented with the reminder that they were "for information only"-- not regulatory requirements--were DNLs of $55 \mathrm{~dB}$ outdoors and $45 \mathrm{~dB}$ indoors. ${ }^{5}$ While the number of people exposed to the highest levels has decreased, a large proportion of the U.S. population lives at levels of environmental noise above DNL $55 \mathrm{~dB}$ outdoors and DNL $45 \mathrm{~dB}$ indoors.

We must remember, however, that the DNL from normal human activity indoors typically exceeds a DNL of $45 \mathrm{~dB}$. Quality of life issues frequently involve sound levels that are quantitatively low, but still annoying. Sound levels need not be very high for annoyance to occur. 


\subsection{The Population Has Changed}

Many changes have taken place in the U.S. population, including the numbers, the density, the ethnic mix, and the attitudes about noise. Each of us makes noise and receives noise. Between 1972 and 2000 the U.S. Population increased from 210 million to 273 million. (At the beginning of the $20^{\text {th }}$ century it was 76 million.)

There is no doubt that noise levels are directly related to population density, and since population densities are increasing in many areas of the country, the number of people adversely impacted by noise is increasing. But the rate of change is different in different areas of the United States. Immigrants are flocking to our major cities and replacing many of our urban inhabitants, who are moving to the suburbs, effectively enlarging the metropolitan areas of many of our cities. This redistribution of urban and suburban populations and the accompanying changes in population densities are accompanied by a shrinking of our rural populations. As the number of people involved with agriculture decreases, and the availability of jobs in the service sector increases, we are witnessing major changes in the demographics and population densities within our country.

These major shifts are accompanied by changes in the numbers of people adversely affected by noise. More and more, noise is becoming an issue of social class, a concept that few discuss openly in our "classless" society. The American with sufficient means can purchase a quiet domicile, one in which noise is not a significant annoyance. The "low-rent" districts tend to be the least desirable real estate, and the ones that are noisiest. Often, they are near major noise sources such as highways, rail lines, airports, industrial districts and commercial districts. "High-rent" suburban districts also experience increases in noise from leaf blowers, weed whackers, larger lawn mowers, heliports, "cigar" speed boats, and so forth.

All of these effects undoubtedly diminish the quality of life in America, and some would assert, adversely affect the health of the American people. But the effect of noise on health is a controversial point. Many European scientists and their colleagues in the World Health Organization characterize excessive noise as a health hazard. But the scientific evidence that noise has a deleterious effect on the health of the exposed populace is not well established, except for hearing loss. There can be no doubt that excessive noise results in annoyance, but whether or not it increases the number of cardiovascular events or other non-auditory health effects is still not firmly established. Hence, while the jury is still out on the adverse physiological health effects of noise, attention continues to be focused on annoyance as the most commonly used indicator of dissatisfaction with the noise environment.

Environmental noise from many sources degrades the quality of life for many millions of people throughout the United States. Sources that are most often reported as causing annoyance for the greatest numbers of people include aircraft, trucks and cars, industrial facilities, outdoor sporting events, construction work, lawn equipment, trains, off-road motorized vehicles, and gun clubs. The noise from these sources surely degrades quality of life. However, these noise 
sources also bring significant improvements to the quality of life for many millions of people. A new National Noise Policy will have to focus on both engineering and public policy while striving to find new and better ways to achieve a more responsible balance which is respectful of both noise makers and noise receivers.

\subsection{The Sound Environment Has Changed}

All aspects of the sound environment have changed in the last 30 years. The number of sources and the number of source types have both increased. Some "old" source types have become quieter (i.e., new-technology aircraft and new dishwashers), some have become noisier (e.g., powered watercraft), and others have remained the same. Certainly most Americans make use of more noise sources now than they did in 1972. Not the only, but certainly the most significant, noise sources throughout the United States are the highway, rail, and air transportation systems. It is well established that transportation noise sources are the most substantial culprit causing the worsening noise environment in the U.S., and although technology has made substantial gains over the past several decades, it is probably not enough to make up for the expected long term growth in the transportation industry.

With regard to highway traffic growth, the generally accepted growth projection is between 3 and 4 percent per annum ${ }^{2}$. Despite the severe blow to all aviation of the terrorist events of 9/11/2001 and the war with Iraq, the industry consensus is that it will have substantial short-term impact but long-term growth will be generally unaffected. ICAO's Forecasting and Economics Subgroup (FESG) projected long-term growth in North American commercial air travel at about $3.3 \%$ over the next twenty years. Rail traffic is also expected to increase.

Increased traffic does not mean that the number of people exposed to environmental noise will increase commensurately. Improvements in technology will compensate for some of the increase in noise exposure. In addition, lack of capacity, particularly on highways and rail systems, will slow the traffic and reduce the noise during periods of under capacity. At times, noise exposure may increase as increases in traffic loads and transportation system capacity overcome the benefits of noise control technology. The tradeoffs in quality of life of these circumstances are obvious.

New power plants can improve the quality of life for some, but no one wants a new plant in their backyard. Most people want the electricity and the reduced air pollution that comes with modern power plants, but not the accompanying noise in the nearby residential neighborhoods. Many folks enjoy snowmobiles, but what about the people who live or vacation near the snowmobile paths? The cost of recreational air travel continues to go down, increasing the quality of life for travelers, and decreasing the quality of life for others who live near airports or on aircraft flight paths. 
Many people have moved to suburban areas, and we now have new noise sources, such as leaf blowers, weed whackers, boom boxes, boom cars, off-road vehicles, jet skis, cell phones, and car alarms, that were not part of the soundscape thirty years ago. Speech interference and interference with leisure time and recreational activities seem to be QOL issues, and recreational activities such as snowmobiles and gun clubs may contribute to the noise that some complain about.

Interference with learning in schools is related to aircraft and other transportation noise intrusions, but of even greater importance is the poor acoustics existing in thousands of classrooms because of excessive reverberation and background noise from heating, ventilating and air-conditioning (HVAC) equipment.

\subsection{Knowledge about Significant Effects Is Still Inadequate}

NCA 72 mandated major research projects, including investigation of significant effects of environmental noise. Important research has also been completed in recent years, but at a much slower pace than when NCA 72 was first established. Important issues must still be considered.

The recent American National Standard (ANSI S12.9, Part 6) describes the incidence of behavioral awakening caused by aircraft noise. While this Standard is accurate as far as it goes, the state of our knowledge does not provide information on awakenings in areas where the residents are unaccustomed to the noise, information on difficulties falling asleep or early awakening, information on going back to sleep after awakening by other causes, or information on sleep effects other than awakening behavior.

Recreation areas where one can find solitude and be free of distracting noise from human activities are decreasing. For example, over 100 National Park Service properties are exposed to noise from air tour flights, Yellowstone as well as other National Park Service properties are exposed to snowmobile noise, and Big Bend Park on the Texas-Mexican border is exposed to Immigration and Naturalization Service and drug interdiction flights. In response to these intrusions, the National Park Service is working vigorously to protect the natural soundscape of federal park lands. This effort includes working with the noise makers, the users of National Park Service facilities, and all levels of government.

\section{A “DUSTED OFF" NCA 72 WILL NOT WORK!}

There is currently no effective NNP in the United States. Certainly a NNP and effective enforcement procedures are very important. But the burden of reversing the trend toward everincreasing noise levels falls on local and state agencies. A NNP should establish clear guidelines on federal vs. local responsibilities, and make clear jurisdictional decisions about what the 
agencies of the federal government should do, and what the state and local agencies should do. A key issue is how much money the state and locals can expect from the federal government, but until their respective responsibilities are defined, this will remain a moot point.

One important component of a new NNP must be the establishment of effective and cooperative engineering noise control programs, in which industry and responsible government agencies work together as partners to reduce noise, improve the quality of life, and achieve the goal set by Congress 30 years ago to achieve an "environment for all Americans free from noise that jeopardizes their health or welfare." There is no doubt that the great advances in aircraft jet engine technology during the past few decades has been achieved by cooperation between engineering partners at the engine and airframe manufacturers and the Federal Aviation Administration (FAA) and the National Aeronautics and Space Administration (NASA). The FAA has served as both regulator and partner of the aircraft industry. Surely similar partnerships could be effective if applied to the highway and rail transportation systems.

\section{REFERENCES}

1 PL 92-574 and amendments.

${ }^{2}$ http://www.fhwa.dot.gov/ohim/ohimstat.htm, the FHWA statistics web site.

${ }^{3}$ PL 92-574: I.2(b)

${ }^{4}$ Office of Noise Abatement and Control, "Information on Levels of Environmental Noise Requisite to protect the Public Health and Welfare with an Adequate Margin of Safety," 550/9-74-004, U.S.

Environmental Protection Agency, (Washington, 1974, pp. 7-8).

${ }^{5}$ Ibid., p. 3 